\title{
Linguistic, Reading, and Transcription Influences on Kindergarten Writing in Children with English as a Second Language
}

\author{
Gina L. Harrison, Keira C. Ogle \& Megan Keilty \\ University of Victoria | Canada
}

\begin{abstract}
The contribution of linguistic, reading, and transcription processes to writing in kindergarten English as a second language (ESL) children and their native-English speaking peers (EL1) were examined. ESL and EL1 performed similarly on one of the two measures of phonological awareness (PA) and on measures of early reading, spelling, and writing. EL1 outperformed ESL on a pseudoword repetition task and on the English vocabulary and syntactic knowledge tasks. ESL outperformed EL1 on a writing fluency measure. Correlation and hierarchical regression results varied as a function of the writing tasks (procedural or generative) and language status. Across language groups, writing tasks that captured children's developing graphophonemic knowledge were associated with a breadth of cognitive, linguistic, and early literacy skills. PA reading, and transcription skills, but not oral vocabulary and syntactic knowledge contributed the most variance to writing irrespective of language status. The results suggest that parallel component skills and processes underlie ESL and EL1 children's early writing when formal literacy instruction begins in kindergarten even though ESL children are developing English oral and literacy proficiency simultaneously.
\end{abstract}

Keywords: L2 kindergarten writing; predictors of early writing; cognitive and linguistic processes; second language learners

\section{Diournal of WRITING RESEARCH}

Harrison, G. L., Ogle, K. C. \& Keilty, M. (2013). Linguistic, reading, and transcription influences on kindergarten writing in children with English as a second language. Journal of Writing Research, 5(1), 61-87. http://dx.doi.org/10.17239/jowr-2013.05.01.3

Contact: Dr. Gina L. Harrison, University of Victoria/Department of Educational Psychollogy \& Leadership Studies, Box 3010 STN CSC, Victoria, BC, Canada V8W 3N4 - harrison@uvic.ca.

Copyright: Earli | This article is published under Creative Commons Attribution-NoncommercialNo Derivative Works 3.0 Unported license. 
Despite the increasing number of children worldwide beginning formal literacy instruction in a language other than their native language, research on the cognitive and linguistic bases of second language (L2) writing development is scarce. For children learning English as a second language (ESL), a great deal is known to date about the development of L2 word level reading and spelling skills effectively informing early reading instruction and intervention in linguistically diverse classrooms. This rich corpus of comparative cross-sectional and longitudinal research indicates that ESL children are mainly indistinguishable from their native English-speaking (EL1) peers on English word-level reading (word recognition and pseudoword decoding) and spelling (word and pseudoword spelling) measures (see August \& Shanahan, 2006 for a review) and ESL and EL1 children's spellings contain similar error patterns and developmental features (Buckwalter \& Lo, 2002; Fitzgerald \& Noblit, 1999; Wade-Woolley \& Siegel, 1997). Children draw on the same basic cognitive and linguistic processes in learning to read and spell in English, irrespective of their oral English proficiency (Jongehan, Verhoeven, \& Siegel, 2007; Lesaux \& Siegel, 2003; Share \& Stanovich, 1995; WadeWoolley \& Siegel, 1997). Regardless of language status, level of sensitivity to the sound structure in the L2 (i.e., phonological awareness) explains the most variance in wordlevel reading and spelling, and is also related to L1 phonological awareness and word recognition in children (Durgunoglu, 2002; Durgunoglu \& Oney, 1999; Gottardo, Yan, Siegel, \& Wade-Woolley, 2001) and in young adults (Harrison \& Krol, 2007). Although spelling has been included as an outcome variable in many of these studies, its prominence in capturing children's knowledge of letter-sound skills in relation to wordlevel reading rather than to writing has been the focus. Research is needed to inform theory on L2 writing and teachers require theoretically and empirically informed approaches to writing in addition to reading instruction in promoting literacy development in their linguistically diverse classrooms (Fitzgerald, 2006; Miller \& McCardle, 2010).

Writing engages children's burgeoning awareness of the symbolic representation of spoken language to convey meaning. Across language systems and orthographies, various "universal attributes" such as sequenced marks, shapes, or scribbles distinguish children's early attempts at writing as a form of communication distinct from their drawings (Puranik \& Lonigan, 2009). As children mature and with continued language and literacy exposure and practice, "language-specific attributes" gain prominence (e.g., the representation of letters corresponding with sounds in alphabetic orthographies through early spelling) and children's writing becomes progressively more conventional within the boundaries of their own language system (Sulzby, 1985; Tolchinksy-Landsman \& Levin, 1987). Most writing models posit qualitative changes in writing form and content based on children's development (Bereiter, 1980; Bereiter \& Scardamalia, 1987) or on the kind of cognitive processes actively engaged by the writer in response to the demands of the writing task (Hayes, 2006; Hayes \& Flower, 1980; Kellogg, 1996). When the language system in which children are learning to write differs from their native language system, as is the case for young ESL children, it is 
unclear whether writing develops along a similar trajectory and whether children draw on the same cognitive, linguistic, and literacy skills and processes in their early writing as their native English speaking peers. The limited evidence to date suggests that when children are processing larger pieces of text in English as an L2, such as when writing or comprehending in reading, they do not achieve the same levels of proficiency as their EL1 peers (Geva, 2006). It has been suggested that this inconsistency between wordlevel and text-level skills among ESL children is oral English proficiency, and there is an association between well-developed oral English skills and English writing achievement (Geva, 2006). This evidence is consistent with Cummins' (1980) Threshold Hypothesis in second language literacy learning where L2 writing skills may be constrained by a certain threshold or level of oral language proficiency in the L2. Indeed, many studies examining ESL and EL1 reading development have converged on a common finding for lower performance by ESL students on oral English language measures assessing syntactic awareness (i.e., children's level of sensitivity to a language's grammatical structure) and vocabulary unsurprising given children's ESL status (Jongejan, Verhoeven, \& Siegel, 2007). In Lesaux \& Siegel's (2003) large-scale longitudinal Canadian study that examined the cognitive and linguistic components of reading development in ESL and EL1-speaking children from kindergarten to Grade 2, ESL children achieved significantly lower scores on a measure of syntactic awareness (i.e., oral cloze) when they first entered school in kindergarten, and even after three years of literacy instruction in English. A similar pattern of differences between ESL and EL1 children on measures of oral vocabulary has also recently been reported by Jean \& Geva (2009). The unique contribution of oral vocabulary to word recognition over and above the variance explained by phonological awareness, rapid automatized naming (RAN), and working memory was examined over two years (Grade 5 to 6) in older Canadian ESL children who had been part of a longitudinal cohort since Grade 1. Despite having received up to six years of literacy instruction immersed in English, older ESL children continued to lag behind EL1 children on two vocabulary measures (i.e., oral receptive vocabulary and written expressive root word vocabulary tasks). The two language groups achieved similar levels of word recognition performance across the same time frame, however. Whether ESL children's oral L2 proficiency contributes to their early writing was examined in the present study.

Two particular models provide a useful conceptual framework from which to examine kindergarten L2 writing and together represent the theoretical underpinning for the present study. In Berninger and Amtmann's (2003) model, young children's writing is constrained at lower-order levels by a lack of automaticity in transcription (handwriting fluency and spelling) processes within a capacity limited working memory architecture. Once these lower-order skills are automatized, attentional and working memory resources are more readily accessible for the process of orchestrating the higher-order skills of generating ideas, planning, organizing, and revising in writing. A lack of automaticity in transcription processes has been empirically linked to components of word specific knowledge (i.e., orthographic, phonological, 
morphological, semantic, and syntactical storage units) that young children are in the process of acquiring within the context of their early literacy experiences and instruction (Berninger, 2009; Berninger \& Swanson, 1994). Since research has shown a persistent disparity between ESL and EL1 children's oral English vocabulary and syntactic awareness (important components of word-specific knowledge necessary for writing according to this model), a main question addressed by the current research is the degree to which these oral language skills impact beginning writing, especially in ESL children. Consistent with this model, we also examined the importance of handwriting fluency and spelling as transcription processes integral to early writing development across writing tasks and language groups. Recent research has highlighted the importance of transcription processes in kindergarten writing with native-English speakers (e.g., Puranik \& Al Otaiba, 2011). Our study extends on this research by examining the contribution of transcription to L2 writing in relation to oral English proficiency in ESL kindergarteners.

Fitzgerald and Shanahan's (2000) model on the relation between reading and writing in literacy development also informs the theoretical basis of the present study. As Fitzgerald and Shanahan (2000, p. 40) so aptly described, reading and writing are "constellations of cognitive processes that depend on categories of knowledge representations at various linguistic levels (phonemic, orthographic, semantic, syntactic, and pragmatic)". These categories of shared knowledge include: (1) metaknowledge, (knowing the purpose of reading and writing, monitoring one's own meaning-making); (2) prior knowledge, domain knowledge, and vocabulary; (3) text attribute knowledge of the phonological, graphophonemic (knowledge about letters, sounds, and their correspondence) attributes that influence word recognition and spelling, syntactic skills, and an understanding of text formats, and (4) procedural knowledge (knowing how to access and use the knowledge in the previous categories). Although English reading and spelling are strongly correlated in populations of young ESL children consistent with their EL1 counterparts (e.g., Chiappe, Siegel, 2002; Lesaux \& Siegel, 2003; Lipka \& Siegel, 2007), and individual differences in spelling are correlated with reading ability in ESL and EL1 children (Chiappe, Siegel, \& Wade-Woolley, 2002; Wade-Wolley \& Siegel, 1997), word-level reading skills, and not writing, have been the main focus of these studies. Few studies have been conducted to date on the relative contribution of important component subskills and processes involved in young children's L2 writing ability and their relationship to early L2 reading ability. Recent research conducted with English L1 kindergarteners has indicated strong associations among early reading and writing variables. Ritchey (2008) reported large proportions of variance (ranging from $53 \%$ to $74 \%$ ) in kindergarten writing (as assessed by letter name writing, sound spelling, real word spelling, and nonsense word spelling) explained by children's performance on early letter naming and letter sound fluency tasks in addition to their performance on phonological processing and global early reading measures. Kindergarten writing ability has also been empirically linked to the development of grade one reading performance after controlling for the effects of general intelligence 


\section{5 | JOURNAL OF WRITING RESEARCH}

(Shatil, Share, \& Levin, 2000). In their study with kindergarten Hebrew-speaking children, Shatil and colleagues (2000) found that varying the order of entry of kindergarten writing into their hierarchical regression model either before or after children's alphabetic knowledge (as assessed by an alphabet identification task and several phonological processing measures) resulted in a different pattern of explained variance to grade one decoding and spelling. Writing lost its contribution to the model once it was entered after alphabetic knowledge, indicating that writing serves as a powerful medium through which children operationalize their increasingly more sophisticated knowledge of the alphabetic principle (i.e., their "awareness of the phonological units represented by letters and the associations between these spoken segments and the graphic symbols).

Consistent with Luria's (1980) classic description about the distinctive cognitive and linguistic processes required for different writing tasks (e.g., copying, dictation, spontaneous writing), not all early writing tasks present the opportunity to draw upon such domain-general alphabetic skills to the same degree. Molfese and colleagues (2010) recently reported correlations between writing and reading skills in 3 to 5 year olds with associations between reading and writing variables that differed in strength as a function of the writing task. Although name writing has typically been considered a salient task related to young children's developing literacy (e.g., Bloodgood, 1999; Haney, Bissonnette, \& Behnken, 2003), Molfese and colleagues reported stronger correlations for scores representing letter writing rather than name writing performance with concurrent norm-referenced measures of the early letter and word recognition administered twice before kindergarten entry, and then again after six months of kindergarten. These researchers distinguished between early writing tasks tapping into procedural knowledge and rote memory, such as name writing and copying, and tasks capturing children's conceptual knowledge of the alphabetic principle and letter-sound associations, such as writing letters or words on demand. Conceptually, the latter tasks are thought to place greater attentional and retrieval demands on children's graphophonemic knowledge (i.e., the relation among letter sounds and letter sound combinations representative of spoken sounds or words). Consistent with the view that early writing tasks vary in the degree to which children must attend to and retrieve early graphophonemic knowledge, children's early writing performance was examined across tasks that placed either low (i.e., procedural) or high (i.e., generative) demands on children's nascent graphophonemic competence. In order to shed insight into the important components of L2 writing, we were particularly interested in between and within group differences as a function of the writing task, and the relation between task demands and the other cognitive, linguistic, and literacy variables across language groups.

In the current study we therefore examined the cognitive, linguistic, and reading correlates of kindergarten writing in ESL and native-English speaking children. A collection of tasks assessing nonverbal reasoning, oral vocabulary, syntactic knowledge, phonological awareness, letter and word identification, letter and word 
spelling, handwriting fluency, and early writing skills in English was administered. Variation in performance across the tasks between ESL and EL1 children was investigated, and correlation and hierarchical regression analyses were conducted. Based on previous research, differences were expected between ESL and EL1 on the oral vocabulary and syntactic knowledge measures, but not between language groups on the measures of phonological awareness. Also consistent with previous research with young ESL populations, we did not expect to see any differences between the groups on the literacy measures assessing early reading and spelling. Whether ESL and EL1 performance would differ on measures assessing writing fluency and on writing tasks assessing procedural knowledge (i.e., name writing, copying words and sentences) and conceptual knowledge on generative tasks (i.e., letter name writing, sound spelling, word writing, sentence writing to dictation) in writing was a main focus. Hierarchical regression analyses examined the relative contribution of oral vocabulary and syntactic knowledge to writing performance across procedural and generative tasks and language groups after accounting for the variance attributed to early reading, phonological awareness, and transcription skills. If oral proficiency in English is important to writing in kindergarten, then we expected that oral vocabulary and syntactic knowledge would add additional variance to writing performance for both language groups.

\section{Method}

\subsection{Participants}

A total of 124 kindergarten children (67 ESL, 56 EL1) from seven schools within the same Canadian urban school district participated in this study. Language status was about equally distributed across schools. Approval from the university's Human Research Ethics Board was obtained. Parents provided signed consent for their children's participation and consent forms were translated into the parents' L1 for the ESL participants. Children also provided their verbal agreement to participate. As is the case in numerous countries today, many Canadian children begin formal literacy instruction in a language other than the language they use at home. In some cities, over $50 \%$ of the population is immigrant, and about $10 \%$ of this population is children under the age of 5 (Statistics Canada, 2006). For Canadian-born children of first or second generation immigrant parents, the first language children learn and continue to use in the home is often not either of the two official languages of English or French (Statistics Canada, 2006). Participating children in both language groups were of similar mean ages (68.5 months for EL1, SD = 3.66 and 67.6 months for ESL, $S D=3.78$ ), and about evenly distributed in terms of gender (32 boys, 35 girls for ESL; 29 boys, 27 girls for EL1). The ESL group was comprised of children whose first language was not English. Punjabi was the L1 of most (93\%) of the ESL children whose parents or grandparents were immigrants from India. Only five of the ESL children spoke a first language other than Punjabi. These languages were: Korean, German, Spanish (two 
students), and Vietnamese. Teacher reports and information from school files validated each child's language status. Participating children lived in predominantly middleclass neighbourhoods with similar socioeconomic status (SES). Median family incomes before taxes ranged from approximately $\$ 55,000-\$ 75,000,30 \%$ of parents had completed high school, and $10-20 \%$ of parents had a university degree. None of the children had documented or reported history of neurological, motor, or developmental disorders, uncorrected visual deficits, or developmental delays. Kindergarten literacy programs within the schools are balanced, and include many opportunities for children to practice with the sound structures of English through games, songs, and direct instruction. Children are also encouraged to regularly write in their journals, receiving corrective feedback on vocabulary, spelling and sentence structure. At the time of the study, the ESL children had been immersed in English language and literacy learning for a period of six months.

\subsection{Measures}

\subsubsection{Non-verbal reasoning}

The Matrix Reasoning subtest from the Wechsler Primary Preschool Scales of Intelligence- $3^{\text {rd }}$ Edition (WPPSI-III, Wechsler, 2001) was administered as a measure of nonverbal ability. Children examined an incomplete visual pattern and pointed to the missing portion from 4 or 5 response options. No verbal responding was necessary. Raw scores based on accuracy were recorded. Internal consistency estimates of $a=.88$ and $\mathrm{a}=.87$ were calculated for EL1 and ESL groups, respectively.

\subsubsection{Oral vocabulary and syntactic awareness}

The Peabody Picture Vocabulary Test-4 ${ }^{\text {th }}$ Edition (PPVT-4, Dunn \& Dunn, 2007) assessed children's receptive vocabulary. On this task, children heard an orally presented word and pointed to one of four pictures that best represented the spoken word. The Syntax Construction subtest from the Comprehensive Assessment of Spoken Language (CASL; Carrow-Woolfolk, 1999) was administered to assess oral English syntactic awareness. This task required children to provide a word, phrase, or sentence that is semantically or grammatically compatible with a picture and verbal stimulus presented by the examiner. Raw scores representing the total number of correct responses across both language measures were recorded. Internal consistency estimates of $\mathrm{a}=.83$ (ESL) and $\mathrm{a}=.88$ (EL1) on the PPVT-IV and $\mathrm{a}=.78(\mathrm{ESL})$ and $\mathrm{a}=.80$ (EL1) on the CASL were calculated.

\subsubsection{Phonological awareness}

Children completed the Sound Matching and Non-word Repetition tasks from the Comprehensive Test of Phonological Processing (CTOPP, Wagner, Torgesen, \& Rashotte, 1999). For Sound Matching, children listened to a target word, followed by three additional words. The task for the first 10 items is to respond to which one of the 
three additional words has the same initial sound as the target word. The task for the second 10 items is to respond as to which one of the three words has the same final sound as the target word. For Non-word Repetition, students listened to pseudowords and were required to repeat the word exactly as it was heard. Raw scores based on accuracy were recorded across both tasks. Internal consistency estimates for Sound Matching were calculated as $\mathrm{a}=.78(\mathrm{ESL})$ and $\mathrm{a}=.82$ (EL1) and for Non-word Repetition, $\mathrm{a}=.78(\mathrm{ESL})$ and $\mathrm{a}=.84$ (EL1).

\subsubsection{Letter identification and word-level reading}

The Letter Identification task was an experimenter-developed measure similar to the task used by Lesaux and Siegel (2003) in their longitudinal study with ESL kindergarteners. Children were presented with a $20.3 \times 27.9 \mathrm{~cm}$ page with all of the letters of the alphabet in lower-case randomly arranged into 4 columns and 7 rows. Consistent with the format used by Lesaux \& Siegel, the examiner randomly selected 12 letters, one at a time, and children pointed to the correct letter. Total correct scores out of 12 were recorded. The Reading subtest from the Wide Range Achievement Test- $3^{\text {rd }}$ Edition (WRAT-3, Wilkinson, 1993) was also administered requiring children to name 15 letters of the alphabet and to read aloud from a list of words that gradually became more difficult. Ceiling rules from the test manual were applied. Total accuracy scores were recorded. Internal consistency estimates were $\mathrm{a}=.87$ (ESL) and $\mathrm{a}=.88$ (EL1) for WRAT-3 Reading.

\subsubsection{Spelling}

The Spelling subtest from the WRAT-3 was administered according to the procedures described in the test manual. The earlier items on this task required children to correctly write the letters that corresponded with the spoken letter name. The second part of this task required children to correctly spell words to dictation. Total accuracy scores were recorded. Coefficient alphas were calculated separately for each group and were $\mathrm{a}=.89(\mathrm{ESL})$ and $\mathrm{a}=.87(\mathrm{EL} 1)$.

\subsubsection{Handwriting fluency}

Children completed the Alphabet Writing task, an index of automaticity in translating orthographic-phonological representations from memory into writing (Abbott \& Berninger, 1993) from the Wechsler Individual Achievement Test- $2^{\text {nd }}$ edition (WIAT-II, The Psychological Corporation, 2002). On this task, children wrote as many letters of the alphabet in order as accurately and as quickly as they could within 15 seconds. Scores were the total number of correctly formed letters produced within the time limit.

\subsubsection{Early writing}

Several tasks from the Written Expression Scales from the Oral and Written Language Scales (OWLS, Carrow-Woolfolk, 1996) assessed children's early writing ability. This scale is comprised of a series of writing tasks that assessed children's ability to write 


\section{9 | JOURNAL OF WRITING RESEARCH}

their first and last names, write the correct letters that corresponded to three spoken letter names, and to three spoken letter sounds, write single words to describe pictures, write two sentences to dictation, and to copy single words and sentences. The tasks were administered and scored using the procedures described in the test manual. Scoring criteria included; (a) the spelling accuracy of their first and last names, (b) the accuracy of the letters produced to letter names or sounds, (c) the spelling and semantic appropriateness of single words written to describe a picture, and (d) the spelling, spacing, and punctuation of sentences copied and written to dictation. Split-half internal consistency coefficients of .76 (ESL) and .75 (EL1) were calculated for the writing scale. Raw scores were summed across the writing tasks. Two raters scored each writing assessment and an inter-rater reliability estimate of .96 was achieved. This high estimate reflects the greater objectivity in item scoring at this early point in writing assessment and is consistent with the estimates reported in the manual for the same ages. Consistent with the research conducted by Molfese and colleagues (2010), children's performance on the tasks was divided into two categories (i.e., procedural and generative) and writing performance was also examined separately. These categories of performance were based on whether children were required to copy (considered more of a rote memory or procedural early writing task) or to generate their own writing (considered more dependent on children's knowledge of the alphabetic principle and their nascent graphophonemic awareness). Procedural tasks included name writing, copying three single words, and copying two sentences. Generative tasks included writing three letter names to dictation, writing three letters that go with their sounds to dictation (i.e., sound spelling), writing the word that goes with each of three pictures, and writing two sentences to dictation.

\subsection{Procedure}

All measures were administered in counterbalanced order across 3 blocks (Oral Vocabulary and Syntax, Reading and Writing, Phonological Awareness) with a fixed order of tasks within blocks. The nonverbal reasoning measure was administered last in all cases. Children completed the tasks individually in one session that lasted about 45 minutes in a quiet room in their school. Data collection took place at the midpoint (i.e., February) of children's kindergarten year.

\section{Results}

Although standard scores were available for all but the alphabet identification measure, analyses were conducted using raw scores consistent with previous research (e.g., Geva \& Yaghoubzadeh, 2005; Jean \& Geva, 2009) as none of the measures have been standardized on ESL populations. Preliminary analyses revealed that there was a normally distributed range of performance on all of the tasks with the exception of the alphabet identification task, which was significantly and negatively skewed $(s>1)$. Further inspection indicated that most students (84\% of ESL and $81 \%$ of EL1) achieved 
scores that were perfect or nearly perfect (i.e., one error) on this measure. Due to this ceiling effect, alphabet identification was dropped from all analyses. No differences due to age or gender were found in preliminary analyses; however, ESL and EL1 groups did differ on the measure of nonverbal reasoning with the EL1 group performing significantly better on this task than the ESL group, $t(123)=2.69, p<.01 d=.526$. Nonverbal reasoning was therefore statistically controlled in subsequent analyses. Descriptive results and performance differences between language groups across the tasks are presented first. The results of a correlational analysis run separately for ESL and EL1 are presented next. Then, the results of a hierarchical regression analyses conducted separately for each language group are presented in order to identify predictors of kindergarten writing ability across tasks (procedural versus generative) and especially in relation to oral English proficiency.

\subsection{ESL and EL1 differences on the cognitive, linguistic, and literacy measures}

Performance differences across the measures between the two language groups were examined first. Table 1 summarizes the descriptive statistics for the kindergarten measures.

Table 1. Descriptive Statistics (based on raw scores) of Kindergarten ESL and EL1 Students' Performance

\begin{tabular}{|c|c|c|c|c|c|c|}
\hline \multirow[b]{2}{*}{ Measures } & \multicolumn{3}{|c|}{$\begin{array}{c}E S L \\
(n=68)\end{array}$} & \multicolumn{3}{|c|}{$\begin{array}{c}\text { EL1 } \\
(n=56)\end{array}$} \\
\hline & Mean & SD & Range & Mean & SD & Range \\
\hline CTOPP Sound Matching & 8.50 & 4.69 & $1-18$ & 9.77 & 5.38 & $1-19$ \\
\hline CTOPP Nonword Rep. & 6.59 & 2.55 & $1-12$ & 8.52 & 2.67 & $2-14$ \\
\hline PPVT-4 & 75.10 & 17.56 & $32-115$ & 105.18 & 14.64 & $73-145$ \\
\hline CASL Syntax Construction & 10.25 & 4.58 & $1-19$ & 17.71 & 4.55 & $2-26$ \\
\hline WRAT-3 Reading & 15.52 & 2.76 & $4-20$ & 16.88 & 5.63 & $5-36$ \\
\hline WRAT-3 Spelling & 14.50 & 2.77 & $5-20$ & 14.64 & 3.29 & $3-22$ \\
\hline Handwriting Fluency & 2.78 & 2.30 & $0-10$ & 1.91 & 2.13 & $0-10$ \\
\hline OWLS - Procedural & 12.28 & 3.54 & $2-7$ & 12.30 & 4.31 & $1-7$ \\
\hline OWLS - Generative & 7.90 & 3.21 & $2-15$ & 8.18 & 3.74 & $2-18$ \\
\hline WPPSI-III Matrix R. & 12.97 & 3.62 & $5-21$ & 14.98 & 4.73 & $5-23$ \\
\hline
\end{tabular}

Note. CTOPP Comprehensive Test of Phonological Processing, PPVT-IV Peabody Picture Vocabulary Test, 4th Edition, CASL Comprehensive Assessment of Spoken Language, WIAT-II Wechsler Individual Achievement Test, 2nd Edition, WRAT-3 Wide Range Achievement Test 3rd Edition, OWLS Oral and Written Expression Scales, WPPSI-III Wechsler Preschool and Primary Scale of Intelligence-3rd Edition. 


\section{1 | JOURNAL OF WRITING RESEARCH}

The apparently low mean score achieved by both language groups on the writing fluency measure, where children quickly wrote the letters of the alphabet in order, is a function of the timed nature of the task (i.e., 15 second time limit). Although we did not use standard scores in our analyses, the raw scores achieved by both groups fell within the average range when compared to age and grade-based norms in the WIAT-II manual. A multivariate analysis of covariance (MANCOVA) on the four oral language measures (sound matching, pseudoword repetition, receptive vocabulary, and syntactic knowledge) was conducted, controlling for nonverbal reasoning. The EL1 group performed significantly better than the ESL group on the tasks assessing pseudoword repetition, $F(1,122)=10.95, p<.001, h^{2}=.08$, receptive vocabulary, $F(1,122)=94.71$, $p<.000, \mathrm{~h}^{2}=.42$, and syntactic knowledge, $F(1,122)=60.72, p<.001, \mathrm{~h}^{2}=.36$. A second MANCOVA was conducted on the five literacy measures (WRAT-3 reading and spelling, alphabet writing fluency, and procedural and generative writing). The ESL group performed significantly better than the EL1 group on the writing fluency measure $F(1,122)=5.96, p<.05, h^{2}=.05$. No other significant differences between the language groups were detected.

\subsection{Relationships among language, reading, and writing measures}

The results of a partial correlational analysis controlling for nonverbal reasoning and run separately for the ESL and EL1 groups are shown in Tables 2 and 3, respectively.

For the ESL group, as seen in Table 2, performance on the individual procedural writing tasks was significantly correlated with only one of the phonological awareness tasks, CTOPP sound matching $(r=.36)$. ESL performance on the individual generative writing tasks was significantly correlated with performance across all linguistic and literacy measures, especially WRAT-3 reading $(r=.73)$ and spelling $(r=.81)$. For the EL1 group, as shown in Table 3, performance on the procedural writing tasks was significantly correlated with CTOPP sound matching $(r=.48)$ and to both WRAT-3 spelling $(r=.31)$ and reading $(r=.28)$. As evident in Table 3 , and similar to the ESL group, the EL1 group's performance on the generative writing tasks also correlated with a broad range of the linguistic and literacy measures, with the exception of pseudoword repetition and syntactic knowledge.

Different patterns of associations were also evident among the writing tasks and the language and literacy measures for both language groups, as also shown in Tables 2 and 3. These results are noteworthy in that such differences represent variation in the cognitive and linguistic processes captured as a function of the unique demands of the writing tasks. In particular, name writing was significantly and moderately correlated with sound matching $(r=.41)$ for the ESL group, and to sound matching $(r=.48)$, WRAT-3 reading $(r=.34)$, and spelling $(r=.32)$ for the EL1 group. 
HARRISON, OGLE \& KEILTY • INFLUENCES ON KINDERGARTEN L2 WRITING | 72

Table 2. Partial Intercorrelations Among Language and Literacy Measures for ESL Controlling for Nonverbal Reasoning

\begin{tabular}{|c|c|c|c|c|c|c|c|c|c|c|c|c|c|c|c|c|}
\hline & 1 & 2 & 3 & 4 & 5 & 6 & 7 & 8 & 9 & 10 & 11 & 12 & 13 & 14 & 15 & 16 \\
\hline 1. CTOPP Sound Matching & - & & & & & & & & & & & & & & & \\
\hline 2. CTOPP Nonword Repetition & $.37^{* *}$ & - & & & & & & & & & & & & & & \\
\hline 3. PPVT-4 & .16 & .16 & - & & & & & & & & & & & & & \\
\hline 4. CASL Syntax Construction & .14 & $.38^{*}$ & $.45^{* *}$ & - & & & & & & & & & & & & \\
\hline 5. WRAT-3 Reading & $.47^{* *}$ & $.28^{*}$ & $.37^{* *}$ & $.36^{* *}$ & - & & & & & & & & & & & \\
\hline 6. WRAT-3 Spelling & $.52^{* *}$ & .23 & $.38^{* *}$ & $.25^{*}$ & $.83^{* *}$ & - & & & & & & & & & & \\
\hline 7. WIAT-II Writing Fluency & $.27^{*}$ & .15 & .14 & -.005 & $.40^{* *}$ & $.38^{* *}$ & - & & & & & & & & & \\
\hline 8. OWLS-Name Writing & $.41^{* *}$ & .05 & 01 & -.09 & .19 & .22 & .16 & - & & & & & & & & \\
\hline 9. OWLS-word copy & -.003 & .04 & -.07 & .02 & -.07 & -.16 & -.21 & .02 & - & & & & & & & \\
\hline 10. OWLS-sentence copy & .04 & .13 & .07 & -.15 & -.007 & .20 & .15 & .15 & -.04 & - & & & & & & \\
\hline 11. OWLS-Letter writing & $.24 *$ & .18 & .23 & .19 & $.68^{* *}$ & $.72^{* *}$ & $.40^{* *}$ & $.24^{*}$ & -.09 & .14 & - & & & & & \\
\hline 12. OWLS-Sound writing & $.47^{* *}$ & .21 & .18 & .04 & $.55^{* *}$ & $.58^{* *}$ & $.28^{*}$ & $.43^{* *}$ & .04 & .20 & $.50^{* *}$ & - & & & & \\
\hline 13. OWLS-Word writing & $.50^{* *}$ & $.32^{* *}$ & $.28^{*}$ & $.25^{*}$ & $.58^{* *}$ & $.63^{* *}$ & $.27^{*}$ & .004 & .00 & -.007 & $.24^{*}$ & $.30^{*}$ & - & & & \\
\hline 14. OWLS-Sentence writing & $.39^{* *}$ & .11 & $.31^{*}$ & $.30^{*}$ & $.50^{* *}$ & $.59^{* *}$ & .08 & .09 & -.17 & .06 & $.25^{*}$ & .23 & $.63^{* *}$ & - & & \\
\hline 15. OWLS-Procedural Total & $.36^{*}$ & .10 & .02 & -.13 & .15 & .24 & .15 & $.90^{* *}$ & .18 & $.52^{* *}$ & $.24^{*}$ & $.45^{* *}$ & -.002 & .07 & - & \\
\hline 16. OWLS-Generative Total & $.55^{* *}$ & $.29^{*}$ & $.34^{* *}$ & $.29 *$ & $.74^{* *}$ & $.81^{* *}$ & $.31^{*}$ & .15 & -.06 & .09 & $.50^{* *}$ & $.52^{* *}$ & $89^{* *}$ & .82 & .16 & - \\
\hline
\end{tabular}

Note. ${ }^{*} p<.05 .{ }^{* *} p<.01$. 
73 | JOURNAL OF WRITING RESEARCH

Table 3. Partial Intercorrelations Among Language and Literacy Measures for EL1 Controlling for Nonverbal Reasoning

\begin{tabular}{|c|c|c|c|c|c|c|c|c|c|c|c|c|c|c|c|c|}
\hline & 1 & 2 & 3 & 4 & 5 & 6 & 7 & 8 & 9 & 10 & 11 & 12 & 13 & 14 & 15 & 16 \\
\hline 1. CTOPP Sound Matching & - & & & & & & & & & & & & & & & \\
\hline 2. CTOPP Nonword Repetition & $.33^{*}$ & - & & & & & & & & & & & & & & \\
\hline 3. PPVT-4 & $.42^{* *}$ & .21 & - & & & & & & & & & & & & & \\
\hline 4. CASL Syntax Construction & $.29^{*}$ & $.30^{*}$ & $.48^{* *}$ & - & & & & & & & & & & & & \\
\hline 5. WRAT-3 Reading & $.51^{* *}$ & .09 & $.28^{*}$ & .23 & - & & & & & & & & & & & \\
\hline 6. WRAT-3 Spelling & $.53^{* *}$ & .18 & $.32^{*}$ & .13 & $.71^{* *}$ & - & & & & & & & & & & \\
\hline 7. WIAT-II Writing Fluency & $.27^{*}$ & $.27^{*}$ & .11 & -.14 & $.52^{* *}$ & $.44^{* *}$ & - & & & & & & & & & \\
\hline 8. OWLS-Name Writing & $.48^{* *}$ & .07 & -.03 & .05 & $.34^{*}$ & $.32 *$ & .14 & - & & & & & & & & \\
\hline 9. OWLS-word copy & .14 & -.10 & .15 & -.03 & .04 & .10 & -.03 & .19 & - & & & & & & & \\
\hline 10. OWLS-sentence copy & .21 & $.27^{*}$ & .07 & - & .04 & .12 & $.45^{* *}$ & .15 & -.03 & - & & & & & & \\
\hline 11. OWLS-Letter writing & .16 & .08 & .09 & -.11 & $.33^{*}$ & $.55^{* *}$ & $.31^{*}$ & .12 & - & .07 & - & & & & & \\
\hline 12. OWLS-Sound writing & .004 & -.01 & -.05 & -.008 & $.27^{*}$ & $.41^{* *}$ & .24 & -.01 & .10 & .09 & $.31 *$ & - & & & & \\
\hline 13. OWLS-Word writing & $.36^{* *}$ & $.29 *$ & $.38^{* *}$ & .12 & $.56^{* *}$ & $.68^{* *}$ & $.37^{* *}$ & .06 & .02 & .23 & $.34^{*}$ & $.35^{*}$ & - & & & \\
\hline 14. OWLS-Sentence writing & $.33^{*}$ & .01 & .24 & .11 & $.72^{* *}$ & $.59^{* *}$ & $.45^{* *}$ & .12 & .13 & .11 & .20 & .19 & $.58^{*}$ & - & & \\
\hline 15. OWLS-Procedural Total & $.48^{* *}$ & .13 & .05 & -.09 & $.28^{*}$ & $.32^{*}$ & $.25^{*}$ & .90 & $.42^{*}$ & $.45^{*}$ & .12 & .03 & .14 & .18 & - & \\
\hline 16. OWLS-Generative Total & $.38^{* *}$ & .19 & $.33^{*}$ & .12 & $.71^{* *}$ & $.78^{* *}$ & $.48^{* *}$ & .09 & .07 & .18 & $.51 *$ & $.49^{*}$ & $.91^{*}$ & $.76^{*}$ & .16 & - \\
\hline
\end{tabular}

Note. ${ }^{*} \mathrm{p}<.05 .{ }^{* *} \mathrm{p}<.01$. 
Although stronger correlations between letter writing and concurrent measures of letter and word recognition in kindergarten native English-speaking students were reported by Molfese and colleagues, we found correlations of similar magnitude between name writing and reading $(r=.34)$, letter writing and reading $(r=.33)$, and sound spelling and reading $(r=.27)$ for the EL1. However, for the ESL group name writing was not significantly correlated with reading, but moderate correlations were evident between reading and letter writing $(r=.68)$ and reading and sound spelling $(r=.55)$. While name writing appears to be drawing on important phonological aspects of language for both groups, its utility as a writing measure varies depending on ESL status. Stronger correlations were found across ESL and EL1 groups between word and sentence writing and reading than between name writing and reading, indicative of these tasks' efficacy in tapping into important shared knowledge especially at the text-level between reading and writing. Among the other procedural writing tasks for EL1 but not for ESL, copying sentences was significantly correlated with performance on pseudoword repetition $(r=$ $.27)$ and syntactic knowledge $(r=.34)$, in addition to alphabet writing fluency $(r=.44)$, indicating that such tasks appear to be capturing EL1 (but not ESL) children's verbal memory, oral syntactic knowledge, and handwriting automaticity.

While there were more associations among the individual generative writing tasks (i.e., letter writing, sound spelling, word writing, and sentence writing) and the language and literacy measures across both language groups, there were a few notable group differences, as also shown in Tables 2 and 3. For example, writing the word that goes with a picture (scored for vocabulary and spelling accuracy) was significantly correlated with both PA tasks and to oral vocabulary, reading, and spelling performance in both language groups. However word writing was significantly correlated with writing fluency $(r=.27)$ and sound spelling $(r=.30)$ only for the ESL group. Sentence writing was significantly correlated with sound matching ( $r=.39 \mathrm{ESL} ; r$ $=.32 \mathrm{EL} 1)$, reading $(r=.49 \mathrm{ESL} ; r=.71 \mathrm{EL} 1)$ and spelling $(r=.58 \mathrm{ESL} ; r=.59 \mathrm{EL} 1)$ for both ESL and EL1 groups, but was also significantly correlated with oral vocabulary $(r=$ $.31)$ for the ESL group, and to writing fluency $(r=.45)$ for the EL1 group. Based on these analyses, it appears that automaticity in retrieving orthographic-phonological representations in writing (as measured by handwriting fluency) is related to writing for ESL at the word level, but at the sentence level for EL1. As also shown in Table 2, oral English vocabulary is related to writing at both the word and sentence level for ESL, and English syntactic knowledge is associated to writing only at the sentence level for ESL. Table 3 also shows that oral English vocabulary and syntactic knowledge is important for EL1 writing at the word level, but neither is associated with writing performance at the sentence level, where writing fluency is prominent only for EL1. This pattern of associations may be explained by EL1 children's greater exposure and practice with English phonology and orthography, and their greater breadth of word-specific knowledge (i.e., vocabulary and syntactic knowledge) in English. These important linguistic differences between the ESL and EL1 groups appear to manifest in a greater 
degree of automaticity (but not accuracy) in writing at the sentence level for the EL1 group in comparison to the ESL group.

\subsection{Predictors of writing ability as a function of the writing task}

Hierarchical multiple regression analyses were conducted separately for ESL and EL1 to examine the contribution of phonological awareness (as measured by the sound matching task), early reading (as measured by WRAT-3 reading), oral vocabulary, and syntactic knowledge (as measured by the PPVT-4 and the CASL-syntax construction, respectively) to kindergarten writing. A second set of analyses was conducted to examine the contribution of transcription (i.e., handwriting fluency and spelling), oral vocabulary, and syntactic knowledge to kindergarten writing. For each analysis all cases were included as no outliers were identified (standardized residuals were less than \pm 3.00). Tolerance indices were examined to identify problems with multicollinearity and none of the variables entered demonstrated a tolerance value of less than .20. The choice of variables and the order of entry into the models was guided by theory on the causal relationship between phonological processing and literacy development in both ESL and EL1, recent research on the importance of handwriting fluency to kindergarten writing (Puranik \& Al Otaiba, 2011), and by the results of the correlational analysis (Tabachnick \& Fidell, 2007). In the first set of analyses, phonological awareness as measured by sound matching was given higher priority of entry after controlling for nonverbal reasoning and was entered in step 2. Sound matching rather than nonword repetition was selected as the measure of phonological processing given its stronger relationship with writing performance across tasks and language groups and due to the performance differences between ESL and EL1 on the nonword repetition task. We were most interested in examining whether oral English vocabulary and syntactic knowledge entered as a block in step 4 would contribute any additional variance once nonverbal reasoning was controlled, and after the variance in English phonological processing and early reading (entered at step 3) was explained. Table 4 summarizes the results for the ESL group.

All of the variables entered into the final model explained $18 \%$ of the variance (adjusted $R^{2}=.115$ ) in procedural writing performance and $61 \%$ of the variance (adjusted $R^{2}=.585$ ) in generative writing performance. For the procedural writing tasks, only sound matching was significant $(p=.003)$ explaining $13 \%$ of the variance in writing performance. On the generative tasks, sound matching was significant, explaining $29.5 \%$ of the variance in writing performance, but early reading explained an additional $28.6 \%$ of the variance. English oral vocabulary and syntactic knowledge did not significantly contribute any additional variance to writing performance across tasks for the ESL group. Both sound matching (beta $=.283, p<.01$ ) and reading (beta $=$ $.577, p<.0001)$ were significant contributors to the final model. 
HARRISON, OGLE \& KEILTY • INFLUENCES ON KINDERGARTEN L2 WRITING | 76

Table 4. Hierarchical Regression Analyses Predicting Writing Performance for ESL From Sound Matching, Early Reading Skills, Oral Vocabulary, and Syntactic Knowledge

\begin{tabular}{|c|c|c|c|c|c|c|c|c|c|c|c|}
\hline \multicolumn{7}{|c|}{ Procedural } & \multicolumn{5}{|c|}{ Generative } \\
\hline Step & Variable & $R^{2}$ & $\Delta R^{2}$ & $\Delta F$ & $p$ & $\beta$ & $R^{2}$ & $\Delta R^{2}$ & $\Delta F$ & $p$ & $\beta$ \\
\hline 1 & $\begin{array}{l}\text { WPPSI-III } \\
\text { MR }\end{array}$ & .012 & .012 & .791 & ns & -.004 & .029 & .029 & 1.95 & ns & -.055 \\
\hline 2 & $\begin{array}{l}\text { CTOPP } \\
\text { SM }\end{array}$ & .141 & .130 & 9.80 & .003 & $.405^{*}$ & .324 & .295 & 28.38 & .0001 & $.283^{* *}$ \\
\hline 3 & $\begin{array}{l}\text { WRAT-3 } \\
\text { Read }\end{array}$ & .142 & .001 & .059 & ns & .031 & .610 & .286 & 46.82 & .0001 & $.577^{* *}$ \\
\hline 4 & PPVT-4 & & & & & .065 & & & & & .086 \\
\hline & $\begin{array}{l}\text { CASL- } \\
\text { Syntax }\end{array}$ & .181 & .039 & 1.47 & ns & -.242 & .616 & .006 & .486 & $\mathrm{~ns}$ & .012 \\
\hline
\end{tabular}

Note. ESL = English as a second language. WPPSI-III MR = Wechsler Primary Preschool Scales of Intelligence-3rd Edition Matrix Reasoning; CTOPP $\mathrm{SM}=$ Comprehensive Test of Phonological Processing-Sound Matching; WRAT-3 READ = Wide Range Achievement Test-3rd EditionReading; PPVT-4 = Peabody Picture Vocabulary Test-4th Edition; CASL-Syntax $=$ Comprehensive Assessment of Speech and Language - Syntax Construction. ${ }^{*} p<.01 .{ }^{* *} p<.001$.

Table 5 summarizes the results for the EL1 group. All of the variables entered into the final model explained $35.7 \%$ of the variance (adjusted $R^{2}=.293$ ) in procedural writing and $60.1 \%$ of the variance (adjusted $R^{2}=.561$ ) in generative writing performance. Once the variance in nonverbal reasoning had been accounted for, only sound matching contributed significant variance $(29.4 \%)$ to procedural writing performance for the EL1 group. For the generative writing tasks, sound matching explained $12.5 \%$ of the variance, after controlling for nonverbal reasoning, and early reading explained an additional $30.6 \%$ of the variance in generative writing performance. Similar to the ESL group, oral English vocabulary and syntactic knowledge did not significantly contribute any additional variance across the writing tasks. In contrast to the ESL group, early reading but not sound matching, was a significant predictor to the final model (beta = $.639, p<.0001)$.

In the final set of analyses, writing fluency as measured by the timed alphabet writing task was entered in step 2 and spelling (as measured by the WRAT-3) was entered at step 3 following nonverbal reasoning across the writing tasks. Whether oral vocabulary and syntactic knowledge (entered as a block in step 4) would add any additional variance after controlling for nonverbal reasoning and after accounting for the variance in writing due to transcription skills was examined. 
77 | JOURNAL OF WRITING RESEARCH

Table 5. Hierarchical Regression Analyses Predicting Writing Performance for EL1 From Sound Matching, Early Reading Skills, Oral Vocabulary, and Syntactic Knowledge

\begin{tabular}{|c|c|c|c|c|c|c|c|c|c|c|c|}
\hline \multirow[b]{2}{*}{ Step } & \multirow[b]{2}{*}{ Variable } & \multicolumn{5}{|c|}{ Procedural } & \multicolumn{5}{|c|}{ Generative } \\
\hline & & $R^{2}$ & $\Delta R^{2}$ & $\Delta F$ & $p$ & $\beta$ & $R^{2}$ & $\Delta R^{2}$ & $\Delta F$ & $p$ & $\beta$ \\
\hline 1 & WPPSI-III MR & .080 & .080 & 4.68 & .035 & $.015^{*}$ & .146 & .146 & 9.23 & .004 & $.169^{* *}$ \\
\hline 2 & CTOPP SM & .294 & .214 & 16.06 & .0001 & $.620^{* * *}$ & .271 & .125 & 9.05 & .004 & $-.012^{* *}$ \\
\hline 3 & WRAT-3 Read & .296 & .002 & .130 & ns & .084 & .576 & .306 & 37.48 & .0001 & $.669^{* * *}$ \\
\hline \multirow[t]{2}{*}{4} & PPVT-4 & & & & & -.084 & & & & & .190 \\
\hline & CASL-Syntax & .357 & .062 & 2.40 & ns & -.232 & .601 & .025 & 1.56 & ns & -.125 \\
\hline
\end{tabular}

Note. EL1 = English as a first language. WPPSI-III MR = Wechsler Primary Preschool Scales of Intelligence-3rd Edition Matrix Reasoning; CTOPP SM= Comprehensive Test of Phonological Processing-Sound Matching; WRAT-3 READ = Wide Range Achievement Test-3rd Edition-Reading; PPVT-4 = Peabody Picture Vocabulary Test-4th Edition; CASL-Syntax $=$ Comprehensive Assessment of Speech and Language - Syntax Construction. ${ }^{* p}<.05 .{ }^{* *} p<$ $.01{ }^{* * *} \mathrm{p}<.001$. 
HARRISON, OGLE \& KEILTY · INFLUENCES ON KINDERGARTEN L2 WRITING | 78

Table 6. Hierarchical Regression Analyses Predicting Writing Performance for ESL From Handwriting Fluency, Early Spelling Skills, Oral Vocabulary, and Syntactic Knowledge

\begin{tabular}{|c|c|c|c|c|c|c|c|c|c|c|c|}
\hline \multicolumn{7}{|c|}{ Procedural } & \multicolumn{5}{|c|}{ Generative } \\
\hline Step & Variable & $R^{2}$ & $\Delta R^{2}$ & $\Delta F$ & $p$ & $\beta$ & $R^{2}$ & $\Delta R^{2}$ & $\Delta F$ & $p$ & $\beta$ \\
\hline 1 & WPPSI-III MR & .012 & .012 & .791 & $\mathrm{~ns}$ & .153 & .029 & .029 & 1.95 & ns & .041 \\
\hline 2 & Writing Fluency & .035 & .023 & 1.58 & ns & .049 & .122 & .094 & 6.93 & .011 & $.013^{*}$ \\
\hline 3 & WRAT-3 Spell & .072 & .037 & 2.55 & ns & .266 & .671 & .549 & 106.77 & .0001 & $.777^{* *}$ \\
\hline 4 & PPVT-4 & & & & & .018 & & & & & .006 \\
\hline & CASL-Syntax & .111 & .038 & 1.34 & ns & -.225 & .679 & .008 & .782 & ns & .098 \\
\hline
\end{tabular}

Note. ESL = English as a second language. WPPSI-III MR = Wechsler Primary Preschool Scales of Intelligence-3rd Edition Matrix Reasoning; WRAT-3 Spell = Wide Range Achievement Test-3rd Edition-Spelling; PPVT-4 = Peabody Picture Vocabulary Test-4th Edition; CASL-Syntax = Comprehensive Assessment of Speech and Language - Syntax Construction. ${ }^{*} \mathrm{p}<.01 .{ }^{* *} \mathrm{p}<.001$. 
Table 6 summarizes the results for the ESL group. None of the variables were significant in contributing to the model for the procedural writing tasks, but the same variables explained $67.9 \%$ (adjusted, $R^{2}=.653$ ) of the variance in generative writing performance. For the generative writing tasks, both writing fluency $(p=.011)$ and spelling $(p=.0001)$ contributed significant variance, explaining $12.24 \%$ (adjusted $R^{2}=$ .094 ) and $67.1 \%$ (adjusted $R^{2}=.549$ ) of the variance, respectively. Only spelling was a significant contributor to the final model (beta $=.777, p<.001$ ) for the ESL group.

After controlling for nonverbal reasoning, none of the transcription or oral language measures contributed significant variance to procedural writing performance for the EL1 group, as shown in Table 7. Similar to the ESL group, the same variables explained $69.3 \%$ (adjusted $R^{2}=.663$ ) of the variance in generative writing performance for the EL1 group. Writing fluency $(p=.0001)$ and spelling $(p=.0001)$ each added significant variance once entered into the model after controlling for nonverbal reasoning explaining $19.6 \%$ (adjusted $R^{2}=.318$ ) and $34.4 \%$ (adjusted $R^{2}=.668$ ) of the variance, respectively. Compared to the ESL group, writing fluency accounted for twice as much variance in generative writing performance for the EL1 group, and spelling accounted for nearly $20 \%$ less variance to the model for EL1. As for the ESL group, only spelling was a significant contributor to the final model (beta $=.653, p<.001$ ).

\section{Discussion}

Our results replicate performance differences between ESL and EL1 children on oral vocabulary and syntactic knowledge measures reported in the literature, but there were no differences between language groups for early reading, spelling, or writing abilities. We also found a greater breadth of skills involved when tasks drew more heavily on children's knowledge of the alphabetic principle and their burgeoning knowledge of letter-sound connections. ESL and EL1 children drew on similar linguistic, reading, and transcription skills to write, but there was some variability between ESL and EL1 children in the relative influence of early linguistic, reading, and transcription skills on writing performance. A detailed discussion of these findings follows.

The disparity we found between ESL and EL1 children's English oral vocabulary and syntactic knowledge, in favour of the EL1 group, has been widely reported in the literature (Geva, 2006). ESL children also achieved lower scores than their native English-speaking peers on the pseudoword repetition task, a measure of phonological processing. This finding is consistent with previous results with young Punjabi-speaking children (Chiappe \& Siegel, 1999) and to the results from other studies on the association between oral language, phonological memory, and literacy acquisition in second language learners, due to the constraints to verbal memory span when language learners are processing pseudowords (e.g., Cheung, 1996; Ellis, 1996; Gathercole \& Thorn, 1998; Harrison \& Krol, 2007; Service, 1992). Irrespective of the linguistic differences between groups, no differences were found between ESL and EL1 groups on 
the other measure of phonological processing (i.e., sound matching) and on the measures of early reading, spelling, or writing (as measured by the procedural and generative tasks), replicating the extant results summarized in the recent synthesis on literacy development in ESL learners (August \& Shanahan, 2006). Importantly our research adds to this literature by examining performance on measures of early writing and presents empirical support to the views expressed by others (e.g., Fitzgerald, 2006) that the developmental features of young ESL children's writing appear to be similar to their native-English speaking peers.

Kindergarten writing performance was examined on tasks that differed across two conceptual dimensions, procedural writing tasks that were considered to draw on rote memory and copying skills, and generative writing tasks considered more reliant on knowledge of the alphabetic principle and graphophonemic awareness skills. This conceptual division of tasks proved fruitful. Whereas limited correlations were found among performance on the procedural writing tasks (name writing, word and sentence copying) and the other linguistic and literacy measures, performance on the generative writing tasks (letter writing, sound spelling, word and sentence writing) was associated with a much broader set of linguistic and literacy measures. Facility with English phonology in addition to accuracy and automaticity in retrieving phonologicalorthographic representations from memory (in letter and word reading or spelling and alphabet writing fluency) were all moderately to strongly associated with kindergarten writing in English as a first or second language when children have to write letters, words, or sentences on demand (i.e., generative writing tasks). As expected, much more of an emphasis is placed on children's growing awareness of English sound structures and their relationship to lexical and sublexical units in writing on these tasks in comparison to rote kinds of tasks requiring children to write their names, or to copy words and sentences.

The analysis of writing performance across the two dimensions also elucidated important differences between ESL and EL1 groups in the type and degree of skills and processes captured by the writing tasks subsumed under each dimension. For example, we replicated Molfese and colleagues findings on the stronger correlations for scores representing letter writing with concurrent measures of early letter and word recognition than for name writing, but for the ESL children only. EL1 children's name writing and letter writing were correlated to a similar degree with a concurrent measure of reading. Apparently, name writing served as more of a rote kind of writing activity for ESL children, unrelated at this point in time to their early graphophonemic competence. We found support for Molfese and colleagues' findings through the inclusion of additional writing measures (word and sentence writing) and observed stronger correlations between word or sentence writing and reading than between name writing and reading across both ESL and EL1 groups. However, the associations between letter or sound writing and reading were nearly twice as strong for the ESL than the EL1 group. 
The ESL group achieved significantly higher scores than EL1 group on the handwriting fluency measure, an index of automaticity in translating orthographic-phonological representations from memory into writing. Writing fluency has been empirically linked to children's developing orthographic-motor integration skills (e.g., Berninger \& Graham, 1998; Berninger, Abbott, Jones et al., 2006); specifically, that in beginning writers the act of writing has less to do with the execution of fine motor skills and more to do with the retrieval of encoded orthographic representations combined with motor patterns (e.g., Berninger \& Amtmann, 2003), a so-called "language-by-hand" (Berninger \& Graham, 1998). In a large cross-sectional longitudinal Canadian study with ESL and EL1 children in grades one to four, Jongejan, Verhoeven and Siegel (2007) found that ESL children outperformed their EL1 peers on a measure of lexical access (i.e., rapid object naming). Our results complement these researcher's findings by demonstrating an ESL advantage for accessing and representing smaller lexical units (i.e., writing alphabet letters quickly on demand). It is noteworthy, however, that the amount of variance explained on generative writing performance due to alphabet writing fluency was $9 \%$ for the ESL group and nearly $20 \%$ for the EL1 group despite an ESL advantage on the alphabet writing fluency task. One possible explanation for this discrepancy is that, unlike EL1, ESL kindergartners may not be transferring their writing fluency skills into actual writing tasks. For these students, retrieving and writing the letters of the alphabet quickly and accurately with little transfer into early writing may be a domainisolated skill that is well developed when assessed in isolation. For the EL1 students, however, this skill may be considered domain-integrated since students are apparently tapping into this transcription skill while they are completing early writing tasks. The novelty of English phonology and orthography may be a mediating factor for the ESL students possibly adding further cognitive demands and additional constraints on working memory to early writing, consistent with Berninger and Amtmann's (2003) capacity limited writing model. There also appears to be a greater degree of automaticity in writing at the sentence level for EL1 students compared to their ESL peers. We found no association between sentence writing to dictation and oral vocabulary and syntactic knowledge in the EL1 group, but did find an association between sentence writing and syntactic knowledge for ESL students. While the EL1 group appears to be drawing on more automatized phonological-orthographic representations in memory for writing sentences to dictation (as found by the correlation between sentence writing and handwriting fluency), the ESL group is relying on their knowledge of English syntax in correctly rendering dictated sentences, a strategy that is unsurprising given their ESL status and comparatively less welldeveloped English syntactic skills.

The results of the hierarchical regression analysis for the transcription variables also indicated that English spelling contributed more variance than handwriting fluency on the generative writing tasks for ESL children compared to EL1. Handwriting fluency contributed nearly twice as much variance to writing (generative) for the EL1 compared to the ESL children. Thus, facility with English transcription processes are important to 
kindergarten writing (particularly when task demands go beyond rote tasks and copying) irrespective of English oral vocabulary and syntactic knowledge, but nativeEnglish speaking children appear to be drawing on a greater degree of automaticity in transcription when they write.

Regardless of task demands and the disparity between ESL and EL1 children's oral English proficiency, ESL children's performance on early writing tasks appear to draw heavily on their knowledge of English phonology, a main focus of literacy instruction in the children's classrooms. Oral vocabulary and syntactic knowledge did not contribute any unique variance to writing across writing tasks (procedural and generative) and between language groups after controlling for nonverbal reasoning and once our models had accounted for variance in (a) phonological awareness (sound matching), reading, and (b) transcription (handwriting fluency and spelling). The correlations among reading and writing variables that we found is also consistent with Fitzgerald and Shanahan's (2000) model on the shared substrata of knowledge between reading and writing. Our findings were particularly focused at the level of text attribute knowledge in this model and provide empirical support for the relation between phonological awareness and graphophonics to early writing in English as an L2. Although the results of our correlational analyses indicated associations between both vocabulary (an element of prior knowledge in Fitzgerald and Shanahan's model) and syntactic knowledge at the word level, and syntactic knowledge at the sentence level in writing for ESL children, it is their knowledge of English phonology (for procedural writing tasks) and English phonology and orthography (for the generative writing tasks) that explains most of the variance in kindergarten writing. An instructional focus on L2 phonology in building lexical and sublexical awareness and representation is considered crucial for L2 literacy (Yeong \& Rickard-Liow, 2010). However, based on the current results, we would extend this view to also include the importance of L2 orthographic awareness (i.e., via reading) and representation (via spelling) as critical to L2 writing development irrespective of kindergarten L2 oral vocabulary and syntactic knowledge.

The present results add to a growing body of research examining the component skills and processes involved in kindergarten writing and highlight important influences on early writing achievement in ESL children concurrently developing oral proficiency and literacy in English. Our findings present only a snapshot into children's early writing skills at a time in their development when a lack of automaticity in transcription processes cognitively constrain the writing process (Berninger \& Swanson, 1994). How older ESL students enact higher-order cognitive skills in recursively planning, writing, editing, and revising their texts within the process of text translation (e.g., Berninger \& Amtmann, 2003) remains to be examined. Whether ESL children experience writing difficulties for the same reasons as their EL1 peers is also unclear. Without information on what component skills and processes contribute to writing difficulties in ESL children, we lack a complete understanding of how best to respond to their 
instructional needs. Longitudinal research following ESL children from kindergarten through school is needed to address these issues.

Our study is also limited by the L2 (English) and the immigrant population studied, comprised mainly of native Punjabi-speakers. The fact that the L1 for the majority of children was the same presents a particular advantage in controlling for language background. Punjabi and English phonological and orthographic systems are quite different (Koul \& Bala, 1992; Mahmood, Hussain, \& Mahmood, 2011), and future research examining language and literacy in children's L1 and L2 would provide insight into any cross-linguistic influences or, as Cummins (1979) described, the linguistic interdependence between a native and a new language in relation to literacy acquisition. Researchers have also suggested controlling for external out-of-school influences such as SES and home literacy on reading and writing in children acquiring other languages (Oller \& Pearson, 2002). Although we did not separate out the influence of SES on literacy in this study, participating children were from similar SES backgrounds. However, due to limited access to parents and difficulty securing a Punjabi interpreter, we were unable to collect information about home literacy or L1 proficiency. Controlling for these outside influences will enhance the quality of future studies.

For immigrants to Canada, becoming orally proficient and literate in English (or French) is a social and economic necessity for participation and inclusion within the mainstream culture. In order to enhance the generalizability of findings and advance knowledge about L2 literacy, disentangling the social, educational, and economic bases for citizens across the globe in becoming orally proficient and literate in other languages (e.g., English as a Foreign Language versus English as a Second Language) is also essential. More research is needed on L2 writing development in other languages and orthographies, the relationship between reading and writing in L2 literacy development, and cross-linguistic comparisons of component writing skills and processes.

Finally, once we had accounted for children's phonological awareness and early reading skills, we did not find that oral vocabulary or syntactic knowledge contributed any unique variance across language groups at this early point in children's writing development. It is possible that the lack of variance due to these oral language skills may be due to the rudimentary nature of the writing tasks where children did not select their own vocabulary or determine their own use of syntax in a free-flowing way. Contrary to what we might have expected based on Cummins' Threshold Hypothesis, ESL children's limited English oral proficiency did not impact their writing performance on these early writing tasks compared to their native English-speaking peers. ESL children had acquired phonological and early reading and spelling skills on par with their EL1 peers, and their early English literacy proficiency rather than linguistic proficiency contributed more to their early writing performance. However, as children progress through school and more demands are placed on text generation in composing, oral vocabulary and syntactic skills may contribute more to writing quality. 
Texts that include more diverse, richer vocabulary with words varying in lexical frequency are often associated with higher overall ratings of writing quality (Schoonen, Van Gelderen, De Glopper et al., 2002). Writers must also draw on their grammatical knowledge in structuring their thoughts beyond the word level to the sentence level in a way that is comprehensible to the reader (Grabe \& Kaplan, 1996). Children's developing morphosyntactic awareness enables them to spell words of greater linguistic complexity (e.g., words that vary in their nonverb, regular verb or irregular verb features) and edit their written texts for misspellings with more precision (Scott, 2004). Although the basis for early writing may be similar between ESL and EL1 children, as our study indicates, research needs to inform how older ESL children confront the semantic and syntactic demands of L2 writing and the associated impact to text quality.

\section{Acknowledgements}

This research was supported by an Investigator Initiated Research Grant from the Canadian Language and Literacy Research Network (CLLRNet) to the first author. We are indebted to the administrators, teachers, and students from the Abbotsford school district for their participation, and to Cheryl Whiting for assistance with data collection.

\section{References}

Abbot, R.D., \& Berninger, V.W. (1993). Structural equation modeling of relationships among developmental skills and writing skills in primary and intermediary grade writers. Journal of Educational Psychology, 85, 478-508. doi: 10.1037/0022-0663.85.3.478

August D., \& Shanahan, T. (2006). Developing Literacy in Second-Language Learners: Report of the National Literacy Panel on Language Minority Children and Youth. Mahwah, NJ: Erlbaum.

Bereiter, C. (1980). Development in writing. In L. W. Gregg and E.R. Stenberg (Eds.), Cognitive processes in writing: An Interdisciplinary approach (pp. 73-93). Hillsdale, NJ: Erlbaum.

Bereiter, C., \& Scardamalia, M. (1987). The psychology of written composition. Hillsdale, NJ: Erlbaum.

Berninger, V. (2009). Highlights of programmatic, interdisciplinary research on writing. Learning Disabilities Research \& Practice, 24(2), 69-80. doi: 10.1111/j.1540-5826.2009.00281.x

Berninger, V., \& Amtmann, D. (2003). Preventing written expression disabilities through early and continuing assessment and intervention for handwriting and/or spelling problems: Research into practice. In H. L. Swanson, K. R. Harris, and S. Graham (Eds.), Handbook of learning disabilities (pp. 345-363). New York, NY: The Guilford Press.

Berninger, V.W., \& Graham, S. (1998). Language by hand: A synthesis of a decade of research on handwriting. Handwriting Review, 12, 11-25.

Berninger, V. W., Abbot, R., Jones, J., Wolf, B., Gould, L., Anderson-Youngstom, M., Shimada, S. \& Apel, K (2006). Early development of language by hand: Composing, reading, listening, and speaking connections, three letter writing modes, and fast mapping in spelling. Developmental Neuropsychology, 29(1), 61-92. doi:10.1207/s15326942dn2901_5 doi: $10.1207 / \mathrm{s} 15326942 d n 2901 \_5$

Berninger, V., \& Swanson, H.L. (1994). Modifying Hayes and Flower's model of skilled writing to explain beginning and developing writing. In E. Butterfield (Ed.), Children's writing: Toward a process theory of development of skilled writing (pp. 57-81). Greenwich, CT: JAI Press.

Bloodgood, J.W. (1999). What's in a name? Children's name writing and literacy acquisition. Reading Research Quarterly, 34, 342-367. doi: 10.1598/RRQ.34.3.5

Buckwalter, J.K., \& Lo, Y.G. (2002). Emergent biliteracy in Chinese and English. Journal of Second Language Writing, 11, 269-293. doi: 10.1016/S1060-3743(02)00088-7 
Carrow-Woolfolk, E. (1996). Oral and Written Language Scales: Written Expression Scale Manual. Circle Pines, MN: American Guidance Service.

Carrow-Woolfolk, E. (1999). Comprehensive Assessment of Spoken Language. Circle Pines, MN: American Guidance Service.

Cheung, H. (1996). Non-word span as a unique predictor of second language vocabulary learning. Developmental Psychology, 32, 867-873. doi: 10.1037/0012-1649.32.5.867

Chiappe, P., \& Siegel, L. S. (1999). Phonological awareness and reading acquisition in English and Punjabi-speaking children. Journal of Educational Psychology, 91(1), 20-28. doi: 10.1037/0022-0663.91.1.20

Chiappe, P., Siegel, L.S., \& Wade-Woolley, L. (2002). Linguistic diversity and the development of reading skills: A longitudinal study. Scientific Studies of Reading, 6, 369-400. doi: 10.1207/S1532799XSSR0604_04

Cummins, J. (1979). Linguistic interdependence and the educational development of bilingual children. Review of Educational Research, 49, 222-251. doi: 10.3102/00346543049002222

Cummins, J. (1980). The cross-lingual dimensions of language proficiency: Implications forbilingual education and the optimal age question. TESOL Quarterly, 14, 175-187. doi: $10.2307 / 3586312$

Dunn, L. M., \& Dunn, L. M. (2007). Peabody Picture Vocabulary Test-4 $4^{\text {th }}$ Edition. Circle Pines, MN: American Guidance Service.

Durgunoglu, A.Y., \& Oney, B. (1999). A cross-linguistic comparison of phonological awareness and word recognition. Reading and Writing: An Interdisciplinary Journal, 11, 281-299. doi: 10.1023/A:1008093232622

Ellis, N. C. (1996). Phonological memory, chunking, and points of order. Studies in Second Language Acquisition, 18, 91-126. doi:10.1017/S0272263100014698

Fitzgerald, J. (2006). Multilingual writing in preschool through $12^{\text {th }}$ grade: The last 15 years. In C. A. MacArthur, S. Graham, and J. Fitzgerald (Eds.), Handbook of Writing Research (pp. 337 354). New York: The Guilford Press.

Fitzgerald, J., \& Shanahan, T. (2000). Reading and writing relations and their development. Educational Psychologist, 35(1), 39-50. doi:10.1207/S15326985EP3501_5

Geva, E. (2006). Second language oral proficiency and second language literacy. In D. August and T. Shanahan (Ed.) Developing literacy in second language learners: Report of the National Literacy Panel on language minority children and youth (pp. 123-140).Mahwah, NJ: Erlbaum.

Geva, E., \& Yaghoubzadeh, Z. (2005). Reading efficiency in Native English speaking and ESL children: The role of oral proficiency and underlying cognitive-linguistic processes. Scientific Studies of Reading, 10, 31-57.

Gottardo, A., Yan, B., Siegel, L.S., \& Wade-Woolley, L. (2001). Factors related to English reading performance in children with Chinese as a first language: More evidence of cross-language transfer of phonological processing. Journal of Educational Psychology, 93, 530-542. doi: 10.1037//0022-0663.93.3.530

Harrison, G.L, \& Krol, L. (2007). Relationship between L1 and L2 word level reading and phonological processing in adults learning English as a second language. Journal of Research in Reading, 30(4), 379-393. doi: 10.1111/j.1467-9817.2007.00351.x

Hayes, J.R. (2006). New directions in writing theory. In C. A. MacArthur, S. Graham, \& J. Fitzgerald (Eds.), Handbook of Writing Research (pp. 28-40). New York: The Guilford Press.

Hayes, J.R., \& Flower, L.S. (1980). Identifying the organization of writing processes. In L. W Gregg and E.R. Stenberg (Eds.), Cognitive processes in writing: An Interdisciplinary approach (pp. 330). Hillsdale, NJ:Erlbaum.

Haney, M.R., Bissonnette, V., \& Behnken, K.L. (2003). The relationship among name writing and early literacy skills in kindergarten children. Child Study Journal, 33, 99-115.

Jean, M., \& Geva, E. (2009). The development of vocabulary in English as a second language children and its role in predicting word recognition ability. Applied Psycholinguistics, 30 153185. doi:10.1017/S0142716408090073 
Jongejan, W., Verhoeven, L. \& Siegel, L.S. (2007). Predictors of reading and spelling abilities in first and second language learners. Journal of Educational Psychology, 99(4). 835-851. doi: 10.1037/0022-0663.99.4.835

Koul, O.N., \& Bala, M.(1992). Punjabi language and linguistics: An annotated bibliograph. Delhi, India: Indian Institute of Language Studies.

Gathercole, S. E., \& Thorn, A. S. C. (1998). Phonological short-term memory and foreign language learning. In A. F. Healy \& L. E. Bourne (Eds.), Foreign language learning: psycholinguistic studies on training and retention (pp. 141-158). Mahwah, NJ: Erlbaum.

Grabe, W., \& Kaplan, R. B. (1996). Theory and practice of writing: An applied linguistic perspective. London, UK: Longman.

Kellogg, R.T. (1996). A model of working memory in writing. In C.M Levy \& S. Ransdell (Eds.), The science of writing: Theories, methods, individual differences, and applications (pp. 57-71). Mahwah, NJ: Erlbaum.

Lesaux, N.K., \& Siegel, L.S. (2003). The development of reading in children who speak English as a second language. Developmental Psychology, 39, 1005-1019. doi: 10.1037/00121649.39.6.1005

Lipka, O., \& Siegel, L.S. (2007). The development of reading skills in children with English as a second language. Scientific Studies of Reading, 11(2), 105-132.

Mahmood, R., Hussain, Q., \& Mahmood, A. (2011). Phonological adaptations of English words borrowed into Punjabi. European Journal of Social Sciences, 22(2), 234-245. Retrieved from http://voyager.library.uvic.ca/vwebv/holdingsInfo?bibld=2628843

Luria, A.R. (1980). Higher cortical functions in man $\left(2^{\text {nd }}\right.$ Edition, B. Haigh Trans.). New York: Basic Books. doi: 10.1007/978-1-4615-8579-4

Miller, B. \& McCardle, P. (2010). Reflections on the need for continued research on writing Reading and Writing: An Interdisciplinary Journal, 24, 12-132. doi: 10.1007/s11145-0109267-6

Molfese, V.J., Beswick, J.L., Jacobi-Vessels, J.L., Armstrong, N.E., Culver, B.L., White, J.M., Ferguson, M.C., Rudasill, K.M., \& Molfese, D.L. (2010). Evidence of alphabetic knowledge in writing: Connections to letter and word identification skills in preschool and kindergarten. Reading and Writing: An Interdisciplinary Journal 24(2) 122-150. doi: 10.1007s11145-0109265-8

Oller, K. K., \& Pearson, B.Z. (2002). Assessing the effects of bilingualism: A background. In D. K. Oller and R. E. Eiler (Eds.s), Language and literacy in bilingual children (pp. 3-21). Clevedon, UK: Multilingual Matters.

Puranik, C.S., \& Al Otaiba, S. (2011). Examining the contribution of handwriting and spelling to written expression in kindergarten children. Reading and Writing: An Interdisciplinary Journal. Advance online publication. doi: 10.1007/s11145-011-9331-x

Puranik, C.S., \& Lonigan, C.J. (2009). From scribbles to scrabble: Preschool children's developing knowledge of written language. Reading and Writing: An Interdisciplinary Journal 24(5) $567-$ 589. doi:10.1007/s11145-0099220-8

Ritchey, K.D. (2008). The building blocks of writing: Learning to write letters and spell words. Reading and Writing: An Interdisciplinary Journal, 21(1-2) 27-47. doi: 10.1007/s11145-0079063-0

Schoonen, R., Van Gelderen, A., De Glopper, K., Hulstijn, J., Snellings, P., Simis, A., \& Stevenson, M. (2002). Linguistic knowledge, metacognitive knowledge and retrieval speed in L1, L2, and EFL writing. In S. Ransdell and M.L. Barbier (Eds.), New directions for research in L2 writing (pp. 101-122). Dordrecht, The Netherlands: Kluwer.

Scott, C. M. (2004). Syntactic contributions to literacy learning. In A. C. Stone, E. R. Silliman, B. J. Ehren, and K. Apel (Eds.), Handbook of language and literacy: Development and disorders (pp. 340-362). New York, NY: The Guilford Press.

Service, E. (1992). Phonology, working memory, and foreign-language learning. Quarterly Journal of Experimental Psychology, 45A, 21-50. 
87 | JOURNAL OF WRITING RESEARCH

Shatil, E., Share, D., \& Levin, I. (2000). On the contribution of kindergarten writing to grade 1 literacy: A longitudinal study in Hebrew. Applied Psycholinguistics, 21, 1-21.doi: $10.1017 /$ S0142716400001016

Statistics Canada (2006). 2006 census. Ottawa, Ontario. Author. Retrieved from http://www.statcan.gc.ca/

Sulzby, E. (1985). Kindergarteners as writers and readers. In M. Farr (Ed.), Advances in writing research volume one: Children's early writing development (pp.127-199). Norwood, NJ: Ablex Publishing.

Tabachnick, B. G., \& Fidell, L. S. (2007). Using Multivariate Statistics: $5^{\text {th }}$ Edition. Boston: Allyn and Bacon.

Tolchinsky-Landsmann, L., \& Levin, I. (1985). Writing in preschoolers: An age-related analysis. Applied Psycholinguistics, 6(3), 319-339. doi:10.1017/S0142716400006238

Wade-Wolley, L., \& Siegel, L.S. (1997), The spelling performance of ESL and native speakers of English as a function of reading skill. Reading and Writing: An Interdisciplinary Journal, 9, $387-$ 406. doi: 10.1023/A:1007994928645

Wagner, R. K., Torgesen, J. K., \& Rashotte, C. A. (1999). The Comprehensive Test of Phonological Processing. Austin, TX: ProEd.

Wechsler, D. (2001). Wechsler Primary Preschool Scales of Intelligence- ${ }^{\text {rd }}$ Edition. Toronto, ON: Pearson Assessment/PsychCorp Canada

Wilkinson, G. S. (1993). The Wide Range Achievement Test-Third Edition. Wilmington, DE: Wide Range Inc. The Psychological Corporation (2002). Wechsler Individual Achievement TestSecond Edition Toronto, ON: Harcourt Canada

Yeong, S. H.M., \& Rickard Liow, S.J. (2010). Phonemic representation and early spelling errors in bilingual children. Scientific Studies of Reading, 14(5), 387-406. doi: 10.1080/10888431003623538 